\title{
Sykepleieres erfaringer med å bruke ESAS til å kartlegge symptomer hos kreftpasienter
}

Elise Marie Ihler

Spesialsykepleier

Seksjon lindrende behandling sengepost, Kreftsenteret, Oslo universitetssykehus, Ullevål

Berit Sæteren

Professor

Institutt for sykepleie og helsefremmende arbeid, Oslomet - storbyuniversitetet

Palliasjon

Kreft

Symptomkartlegging

sykepleier

Kvalitative dybdeintervjuer

Sykepleien Forskning 201914 (79585) (e-79585)

DOI: 10.4220/Sykepleienf.2019.79585

\section{Sammendrag}

Bakgrunn: Pasienter med kreft i palliativ fase har ofte et sammensatt symptombilde med mange plagsomme symptomer som reduserer pasientens livskvalitet.

Symptomopplevelsen er subjektiv. En forutsetning for effektiv symptomlindring er systematisk symptomkartlegging, der bruk av standardiserte kartleggingsverkt $\varnothing \mathrm{y}$ som Edmonton Symptom Assessment System (ESAS) anbefales. På tross av denne anbefalingen er det utfordringer med å bruke ESAS i klinisk praksis. Sykepleiere har en sentral rolle i kartlegging og symptomlindring og er derfor brukere av ESAS.

Hensikt: Studien skal utforske sykepleieres erfaringer med å bruke ESAS for å kartlegge symptomer hos sykehuspasienter med kreft i palliative fase. 
Metode: Vi foretok kvalitative dybdeintervjuer av seks sykepleiere fra to onkologiske sengeposter fra et sykehus i Helse S $\varnothing$ r- $\varnothing$ st-regionen. En semistrukturert intervjuguide ble benyttet til intervjuene. Vi analyserte datamaterialet med Malteruds systematiske tekstkondensering.

Resultater: Sykepleierne anser ESAS som et nyttig kartleggingsverkt $\varnothing y$ som gir et bilde av pasientens subjektive symptomopplevelse, og som er en inngangsport for samtale med pasientene om deres symptomer, noe som igjen bidrar til bedre symptomlindring og livskvalitet for pasientene. Rutinemessig bruk vektlegges for å oppnå skjemaets formål. Likevel brukes ESAS i varierende grad, noe som påvirker hvorvidt skjemaet bidrar til å systematisere symptomkartleggingen. Sykepleierne identifiserte flere barrierer og forbedringstiltak for rutinemessig bruk av ESAS.

Konklusjon: Dersom ESAS skal bidra til å systematisere kartleggingen, bør skjemaet brukes rutinemessig. Derfor bør fremtidig forskning vektlegge å identifisere barrierer og evaluere tiltak som kan forebygge barrierene som fører til den varierende bruken av ESAS.

Pasienter med uhelbredelig kreft har ofte sammensatte og plagsomme symptomer som påvirker deres livskvalitet (1-5). Forskning viser at pasientgruppen i snitt rapporterer 9-18 symptomer $(2,3,6)$. Fatigue, smerte, kvalme, nedsatt matlyst, dyspné, angst, søvnvansker, depresjon og eliminasjonsvansker er de mest rapporterte $(2,6,7)$.

Verdens helseorganisasjon (WHO) definerer palliative care som en tilnærming som har til hensikt å forbedre livskvaliteten til pasienter og deres pårørende i møte med livstruende sykdom.

Livskvaliteten kan forbedres gjennom å forebygge og lindre lidelse ved hjelp av tidlig identifisering, grundig vurdering og behandling av smerte og andre problemer av fysisk, psykososial og åndelig art (8). Den palliative fasen er fra sykdommen erkjennes uhelbredelig frem til pasientens dødstidspunkt (1).

\section{Systematisk symptomkartlegging}

En forutsetning for effektiv symptomlindring er systematisk symptomkartlegging, der bruk av standardiserte kartleggingsverkt $\varnothing y$ anbefales $(1,2,4,9)$. Systematisk kartlegging er også viktig fordi forskning viser at helsepersonell har en tendens til å undervurdere pasientenes symptomer. Resultatet blir udiagnostiserte symptomer og manglende symptomlindring $(2,10,11)$. 
Siden symptomopplevelsen alltid er subjektiv, anbefales selvrapporteringsverkt $\varnothing \mathrm{y}$, slik at pasienten kan beskrive sin symptomopplevelse $(1,2,4)$. Nasjonalt handlingsprogram for palliasjon i kreftomsorgen (1) anbefaler Edmonton Symptom Assessment System (ESAS) som det standardiserte kartleggingsverktøyet.

ESAS ble utviklet av Bruera og medarbeidere (12) i 1991 som et klinisk kartleggingsverktøy med formålet om å bedre kartleggingen av pasientenes symptomer, bidra til at flere symptomer oppdages og gi bedre kvalitet på pasientens behandling og pleie (7).

ESAS er et validert og internasjonalt anerkjent selvrapportingsskjema som dekker ni symptomer (smerte, slapphet, døsighet, kvalme, matlyst, tungpust, depresjon, angst og generelt velvære) og et tilleggsspørsmål (annet problem). Symptomene skåres med en numerisk skala (NRS) fra o til 10 (fra ingen til verst tenkelig plage). Ved kartlagt smerte benyttes et kroppskart der pasienten beskriver smertens karakter og lokalisasjon $(7,9,12,13)$.

\section{Ikke alle bruker ESAS}

Til tross for at det er anerkjent at systematisk symptomkartlegging er essensielt for å lindre pasientens symptomer, er det utfordrende å få helsepersonell til å bruke $\operatorname{ESAS}(2,4,14-16)$.

Ifølge fagprosedyren til ESAS (9) er helsepersonell som har daglig ansvar for pasientbehandling og pleie, brukere av ESAS. Sykepleierens fundamentale oppgave er å ivareta pasientens grunnleggende behov, og sykepleieren er i direkte kontakt med pasienten gjennom hele døgnet (5).

Kreftsykepleie er en vanlig spesialisering blant sykepleiere som arbeider med den palliative pasientgruppen.

Kreftsykepleierens lindrende funksjon omfatter å utføre sykepleietiltak som begrenser omfanget av pasientens fysiske, psykiske, sosiale og åndelige eller eksistensielle belastninger.

For å ivareta pasienten må sykepleieren til enhver tid kartlegge pasientens ressurser og behov og iverksette og evaluere tiltak. Systematisk symptomkartlegging med ESAS er derfor en sentral sykepleieoppgave $(5,15,17)$. 


\section{Tidligere forskning}

Vi utførte litteraturs $\varnothing \mathrm{k}$ i Cinahl, Medline, Cochrane, PubMed og McMasterPluS i april-mai 2017 og april-mai 2018, som indikerer at det er begrenset med studier om sykepleieres erfaringer med systematisk kartlegging ved hjelp av ESAS. Fitch og medarbeidere (15) st $\varnothing$ tter denne tendensen.

Når sykepleieren har en så sentral rolle med å kartlegge pasientenes symptomer, er det behov for å gå i dybden for å belyse hvordan sykepleiere bruker ESAS i klinisk praksis.

\section{Hensikten med studien}

Hensikten med studien var å utforske sykepleieres erfaringer med å bruke ESAS for å kartlegge symptomer hos sykehuspasienter med kreft i palliativ fase. Vi ønsket å besvare følgende forskningsspørsmål: Hvilke erfaringer har sykepleiere med å bruke ESAS for å kartlegge symptomer hos pasienter med kreft i palliativ fase?

\section{Metode}

\section{Design}

Studien har et fortolkende kvalitativt design med dybdeintervjuer.

\section{Utvalg}

Et strategisk utvalg ble benyttet. Vi rekrutterte sykepleiere fra to onkologiske sengeposter fra et sykehus i Helse Sør-Øst. Inklusjonskriteriene var at deltakerne måtte være sykepleiere, gjerne med relevant videreutdanning.

Sykepleierne skulle arbeide med pasienter med kreft i palliativ fase i sykehussetting. I tillegg skulle de ha kunnskap og erfaring med symptomkartlegging og ESAS, minst to års relevant arbeidserfaring og minimum 50 prosent stilling.

Deltakerne ble rekruttert via avdelingssykepleierne. De videresendte deltakerforespørselen til sine sykepleiere, som frivillig kunne melde seg til å delta. Førsteforfatteren intervjuet seks sykepleiere fra november til desember 2017.

Alle deltakerne var kvinner, hvorav fem deltakere var kreftsykepleiere. Gjennomsnittsalderen var 37,2 år, gjennomsnittlig yrkeserfaring var 13,2 år, og gjennomsnittlig ansettelsestid var 6,3 år. Se tabell 1 for deltakerinformasjon. 
Tabell 1. Informasjon om deltakerne

\begin{tabular}{l|c|c|c|c|c}
\hline Deltakere & Kjønn & Videreutdanning & Yrkeserfaring (år) & $\begin{array}{c}\text { Ansettelsestid } \\
\text { på aktuell post (år) }\end{array}$ & Alder \\
\hline Sykepleier 1 (S1) & Kvinne & Kreftsykepleie & 17 & 10 & 40 \\
Sykepleier 2 (S2) & Kvinne & Kreftsykepleie & 6 & 2 & 30 \\
Sykepleier 3 (S3) & Kvinne & Kreftsykepleie & 6,5 & 6 & 28 \\
Sykepleier 4 (S4) & Kvinne & Kreftsykepleie & 28 & 11 & 49 \\
Sykepleier 5 (S5) & Kvinne & Kreftsykepleie & 20 & 7 & 41 \\
Sykepleier 6 (S6) & Kvinne & Ingen & 1,5 & 1,5 & 35 \\
& & & & & \\
\hline
\end{tabular}

\section{Datainnsamling}

Vi utviklet en semistrukturert intervjuguide $(18,19)$.

Spørsmålene omfattet bruk av ESAS i praksis, skjemaets

bidrag til systematisk kartlegging, samsvar mellom praksis og fagprosedyren, fordeler og utfordringer og betydning for pasientens behandling. Intervjuene fant sted på deltakernes arbeidssted og varte i 30-45 minutter. Intervjuene ble dokumentert med lydopptak, som førsteforfatteren transkriberte.

\section{Analyse}

Vi brukte en fortolkende tverrgående analyse basert på Malteruds systematiske tekstkondensering. Analysemetoden består av fire trinn. Se tabell 2 for utdrag av analysen. I trinn 1 «Helhetsinntrykk» ble materialet lest gjennom flere ganger for å få et helhetsinntrykk og finne foreløpige temaer.

I trinn 2 «Meningsbærende enheter» skilte vi relevant og irrelevant tekst slik at vi identifiserte meningsbærende enheter som belyser forskningsspørsmålet, og sorterte dem i kodegrupper.

I trinn 3 «Kondensering» hentet vi systematisk ut mening ved å kondensere og abstrahere innholdet i de meningsbærende enhetene i kodegruppene og sortere i ytterligere undergrupper. Kondensat ble laget til hver undergruppe, med gullsitat som oppsummerer hovedelementene. I det siste trinnet «Syntese» ble kunnskapen sammenfattet i form av fortolkende synteser, som dannet grunnlaget for beskrivelser, begreper og resultater (19). 
Tabell 2. Systematisk tekstkondensering - utdrag fra analysen

\begin{tabular}{|c|c|c|c|c|c|c|}
\hline \multirow{2}{*}{$\begin{array}{l}\text { Helhetsinntrykk } \\
\text { Villnis til foreløpige } \\
\text { temaer } \\
\text { Foreløpige temaer }\end{array}$} & \multicolumn{2}{|c|}{$\begin{array}{l}\text { Meningsbærende enheter } \\
\text { Foreløpige temaer til koder og sortering }\end{array}$} & \multicolumn{2}{|c|}{$\begin{array}{l}\text { Kondensering } \\
\text { Koder til abstrahert meningsinnhold }\end{array}$} & \multicolumn{2}{|c|}{$\begin{array}{l}\text { Syntese } \\
\text { Kondensering til beskrivelser, } \\
\text { begreper og resultater }\end{array}$} \\
\hline & Kode-gruppe & Meningsbærende enheter & Undergruppe & Kondensat & Syntese & Ny overskrift \\
\hline Et godt verktøy & $\begin{array}{l}\text { Erfaringer } \\
\text { med ESAS } \\
\text { som et godt } \\
\text { verktøy }\end{array}$ & $\begin{array}{l}\text { «En får ofte en veldig god samtale } \\
\text { med pasienten, så jeg opplever } \\
\text { egentlig at det er en god inngang- } \\
\text { sport.» (S1) } \\
\text { «Når jeg får pasienter til å fylle ut } \\
\text { et ESAS, giør jeg det enten sammen } \\
\text { med dem, eller hvis de fyller det ut } \\
\text { selv, går jeg alltid inn etterpå og så } \\
\text { snakker vi om de punktene hvor de } \\
\text { har en skår over 3. En får ofte en } \\
\text { veldig god samtale og veldig mye } \\
\text { informasjon.» (S1) } \\
\text { «Da opplever jeg at en får en ganske } \\
\text { fin samtale og kan avklare hva de } \\
\text { selv har gjort i forhold til det, og om } \\
\text { de ønsker hjelp i forhold til det, og } \\
\text { hva vi eventuelt kan tilby.» (S1) } \\
\text { «Jeg opplever at det egentlig } \\
\text { kommer frem ting som de rett og } \\
\text { slett ikke visste at de kunne få hjelp } \\
\text { til.» (S1) } \\
\text { «Det gir pasienten et fint rom til å } \\
\text { fortelle hvordan de har det, som er } \\
\text { veldig viktig.» (S1) }\end{array}$ & $\begin{array}{l}\text { Åpner for } \\
\text { samtale med } \\
\text { pasienten }\end{array}$ & $\begin{array}{l}\text { «Det gir et fint rom } \\
\text { for pasienten til å } \\
\text { fortelle hvordan de } \\
\text { har det.» (S1) } \\
\text { "Da opplever jeg } \\
\text { at en får en ganske } \\
\text { fin samtale og kan } \\
\text { avklare hva de selv } \\
\text { har gjort i forhold til } \\
\text { det, og om de ønsker } \\
\text { hjelp i forhold til det, } \\
\text { og hva vi eventuelt } \\
\text { kan tilby.» (S1) } \\
\text { Gullsitat: } \\
\text { "En får ofte en } \\
\text { veldig god samtale } \\
\text { med pasienten, så } \\
\text { jeg opplever egentlig } \\
\text { at det er en god inn- } \\
\text { gangsport.» (S1) }\end{array}$ & $\begin{array}{l}\text { ESAS fungerer som } \\
\text { en inngangsport } \\
\text { for samtale som gir } \\
\text { pasienten rom til å } \\
\text { fortelle sykepleier- } \\
\text { en om deres symp- } \\
\text { tom-opplevelse og } \\
\text { hva de ønsker hjelp } \\
\text { med. }\end{array}$ & $\begin{array}{l}\text { En dør- } \\
\text { åpner for } \\
\text { inngående } \\
\text { samtale }\end{array}$ \\
\hline
\end{tabular}

\section{Etiske overveielser}

Studien er godkjent av Norsk senter for forskningsdata (NSD) med referansenummer 55706. Det var frivillig å delta, og vi innhentet signert samtykke. Alle opplysninger og data er behandlet konfidensielt, anonymisert og oppbevart etter forskningsetiske forskrifter (19).

\section{Resultater}

Det var mange likhetstrekk og få forskjeller i sykepleiernes erfaringer. Gjennom analysefasen fremsto to overordnede temaer med underpunkter, som er «et nyttig verktøy for å kartlegge pasientenes symptomer» og «varierende bruk av ESAS i klinisk praksis».

\section{Et nyttig verktøy for å kartlegge pasientenes symptomer}

\section{Pasientens subjektive symptombilde}

ESAS beskrives som et nyttig verktøy for å kartlegge pasientenes symptomer: «ESAS inneholder de viktigste punktene for å kunne kartlegge pasienten.» (S4) og «Du får et fint bilde av hvordan pasienten har det, og hvilke ting vi må ta tak i.» (S3)

\section{«Det er pasientens egen kartlegging. Det er ikke vi som anslår noe.»}


ESAS gir et Øyeblikksbilde, og sykepleierne kan følge pasientens symptomer over tid. Sykepleierne fremhevet spesielt det at ESAS får frem pasientens opplevelse av sine symptomer: «Du får pasientens subjektive opplevelse av de forskjellige symptomene.» (S6) og «Det er pasientens egen kartlegging. Det er ikke vi som anslår noe.» (S2)

\section{En døråpner for inngående samtale}

Sykepleierne erfarer at ESAS åpner for samtale der pasienten kan gi uttrykk for sine symptomer, og sykepleieren får en oversikt over pasientens symptomer og behov: «Det er ikke mange pasienter som sier rett ut hvordan de har det, men med ESAS kan det bli lettere å åpne for samtale.» (S6) og «ESAS gjør pasienten i stand til selv å tenke gjennom hvordan de har det og komme i god samtale med sykepleierne.» (S3)

Sykepleieren opplever også at de fanger opp mer med ESAS: «Jeg føler man ofte fanger opp mer enn hvis man bare spør «Hei, hvordan har du det i dag?» (S3) Dette mener sykepleierne igjen har en positiv innvirkning på pasientens holdning til ESAS: «Pasienten ser at det de gir uttrykk for, blir tatt på alvor, og at det blir satt inn tiltak som fungerer for dem. Da blir det mer motiverende å svare på ESAS igjen.» (S6)

\section{Varierende bruk av ESAS i klinisk praksis}

\section{Mangelfull oppfølging av rutiner}

Sykepleierne fortalte at de har ansvaret for å dele ut ESAS, hjelpe med utfyllingen, gjennomgå svarene med pasientene, ta med ESAS på legevisitten eller tverrfaglige møter og elektronisk journalføre ESAS i et forløpsskjema. ESAS ble hyppigst brukt ved innleggelser, ved kompliserte symptombilder eller ved kontakt med palliativt team. Sykepleierne vektla hvor viktig det er å bruke ESAS rutinemessig og følge opp svarene.

På tross av det sykepleierne fortalte, ble ESAS brukt i varierende grad, og det ble ofte bare «et papir i bunken». ESAS ble ofte brukt når den enkelte sykepleieren vurderte at ESAS var nødvendig: «Vi synes at ESAS er et godt verkt $\varnothing y$. Vi bruker det litt sånn fast. Vi bruker det fast ved innkomst og én dag i uken. Så skal det brukes når man har forandring. Det er det som er planen, men jeg tror ikke vi alltid er så gode til å gjøre det.» $(\mathrm{S} 1)$ 
Mangel på tid var en barriere som sykepleierne fremhevet:

«Det er travelt, og du prioriterer så godt du kan. Da blir ofte ESAS glemt eller nedprioritert.» (S1) I tillegg var det vanskelig å følge opp ESAS når de syntes det var tidkrevende å dokumentere skjemaet elektronisk, og når kroppskartet ikke kan dokumenteres elektronisk på en systematisk måte.

\section{Uklare rutiner fører til ulik praksis}

Rutinene ble oppfattet som uklare, og sykepleierne uttrykte bekymring for hvilken konsekvens dette har: «Vi har litt ulik praksis, og vi får fort ulike svar av den samme pasienten. Siden det ikke er noen klare rutiner for ESAS på avdelingen, går vi kanskje glipp av mange symptomer.» (S6) og «Hvis pasienten ikke har noen opplevelse av at det blir gjort noe med ESAS, ser de kanskje ikke nytten av ESAS. Da blir ESAS bare mas.» (S6)

Varierende bruk resulterer $i$ at sykepleierne opplever at ESAS i liten grad bidrar til å systematisere kartleggingen. Sykepleierne påpekte også at helsepersonellet ofte vektla egne kliniske vurderinger av pasientens symptombilde, selv om de ofte ikke syntes det var like effektivt som å bruke ESAS: «Vi tror nok at vi er flinkere til å lese og forstå pasienter enn det vi egentlig er. Når du fyller ut et ESAS, har pasienten det nesten alltid annerledes enn en tror.» (S1)

\section{Manglende vektlegging på å bruke ESAS}

En viktig barriere som sykepleierne trakk frem, var manglende oppmerksomhet på ESAS. Denne barrieren gjaldt flere faggrupper, spesielt legene, som viste liten interesse for ESAS med mindre sykepleierne oppfordret dem. Det fikk heller ingen konsekvenser hvis ESAS ikke ble brukt: «Bruker vi ikke ESAS, får vi ikke avvik.» (S5)

Det var også lite vektlegging av ESAS i undervisningen samt lite kjennskap til ESAS' fagprosedyre. Sykepleiernes forslag om hvordan ESAS kan brukes mer rutinemessig, innebar at alt helsepersonell skulle legge mer vekt på ESAS. ESAS skulle være tema i undervisningssammenheng, og ressurspersoner og ledelsen skulle vise større engasjement:

«Jeg tror vi må sette mer fokus på undervisning, hva man skal bruke ESAS til, og hvordan man skal følge opp svarene.» (S2) og «Hvis det hadde vært mer fokus på det fra fagsykepleier eller ledere, hadde vi kanskje automatisk blitt bedre på det.» 
Større eksponering av ESAS for tverrfaglige grupper ble også foreslått: «Vi bør sikkert ta det med til dem oftere, og de andre faggruppene bør kanskje også ha mer fokus på det.»

\section{Diskusjon}

\section{Styrken ved å bruke ESAS}

Siden symptomopplevelse alltid er subjektiv, vil det være viktig å bruke et selvrapporteringsverktøy, slik at pasientenes symptomopplevelse kommer frem (1). Sykepleierne i denne studien opplever at ESAS er et nyttig kartleggingsverktøy

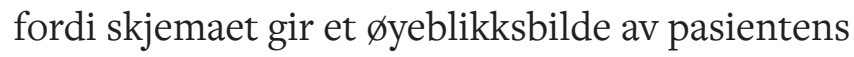
symptomopplevelse, flere symptomer fanges opp, og symptomer og effekten av tiltak kan følges over tid.

De samme forholdene støttes av tidligere litteratur (1, 2, 9, 20-23). Pasienter med høy ESAS-skår har ofte en høy symptombyrde (24). Pasienter med kreft i palliativ fase opplever ofte mange symptomer som kan endre seg raskt eller over tid, og som kan påvirke hverandre negativt (2-4). De ovennevnte fordelene med ESAS vil derfor kunne bidra til at symptomkartleggingen blir mer systematisk og effektiv.

Samtidig kan misforståelser rundt ESAS påvirke, slik at skjemaet kanskje ikke representerer pasientens reelle symptomopplevelse. Et eksempel er feiltolkninger av begrepsdefinisjoner som «døsighet» og «slapphet». Mange kan synes det er vanskelig å forstå forskjellen på disse begrepene.

Et annet eksempel er feiltolkning av NRS-skalaen. På ESAS graderes «nedsatt matlyst» fra $\mathrm{O}=$ ikke nedsatt matlyst til 10 = verst tenkelig nedsatt matlyst. Pasienter har en tendens til å tro at en høy skår betyr god matlyst (2). Hensiktsmessig bruk krever derfor at sykepleiere har tilstrekkelig kunnskap om ESAS og kan veilede pasienten.

\section{Viktig med god kommunikasjon}

For å få frem pasientenes symptomopplevelse er det nødvendig med god kommunikasjon mellom pasienten og sykepleierne (1). Sykepleierne i denne studien erfarer at ESAS åpner for samtale med pasienten om vedkommendes symptomer. Sykepleiernes erfaringer samsvarer med resultater fra tidligere litteratur $(1,9,20-22,25)$. 


\section{symptomer.»}

Siden ESAS ikke dekker alle symptomene pasienten kan

oppleve, bør ESAS brukes som et utgangspunkt for samtale $(20,21)$. Ved å begynne samtalen rundt ESAS kan sykepleieren fange opp flere symptomer, også de som ikke etterspørres i skjemaet. Deretter kan sykepleieren gå i dybden av symptomets eller symptomenes karakter og hvordan de(t) påvirker pasienten, noe som igjen kan bidra til at pasienten føler seg mer sett og tatt på alvor.

Dersom sykepleierne ikke bruker et systematisk kartleggingsverktøy, kan det medføre at pasientens symptomer overses. ESAS er et verkt øy og et utgangspunkt. For å vurdere pasientens symptombilde på en helhetlig måte må sykepleieren i tillegg anvende faglig skjønn (26).

\section{ESAS må brukes rutinemessig}

Sykepleierne i denne studien er opptatt av at ESAS må brukes rutinemessig hvis symptomkartleggingen skal bli systematisk. Dette synspunktet st $\varnothing t t e s$ av nasjonale retningslinjer og fagprosedyren $(1,9)$. Forskning viser at pasienter har mange symptomer de ikke rapporterer på egen hånd, og som ikke blir identifisert. Bruk av selvrapporteringsverktøy som ESAS vil derfor ha en vital rolle i kartleggingen (6).

Resultatene kan derfor tolkes i retning av at rutinemessig bruk er en forutsetning for at skjemaet skal bidra til systematisk symptomkartlegging, og igjen bedre symptomlindring. Forholdet st $\varnothing t t e s$ av Chen og Hollis (27), som anbefaler rutinemessig bruk av selvrapporteringsverkt $\varnothing y$ som ESAS, da det sikrer bedre kommunikasjon mellom pasienten og helsepersonellet.

Videre bidrar systematisk kartlegging til at flere symptomer blir identifisert, at effekten av behandlingstiltak kan evalueres, samt at pasientene rapporterer større tilfredshet med behandlingen.

\section{Hvordan motvirke barrierer ved å bruke ESAS}


Både sykepleierne i denne og andre studier fremhever at kartlegging og lindring av pasientens symptomer er et av sykepleiernes ansvarsområde (20-22). I denne studien presiserer sykepleierne hvor viktig det er at ESAS brukes rutinemessig, og hvilket ansvar de har for å sikre god kartlegging.

Man kan stille spørsmål ved hvorfor sykepleiere bruker skjemaet så variert siden de er så bevisste på nytten av ESAS. Her skiller sykepleiernes erfaringer seg fra andre studier, der flertallet rapporterer at de alltid eller nesten alltid bruker ESAS og oppfordrer pasienter til å bruke ESAS (20-22).

Sykepleierne bemerker at deres varierende bruk kan føre til at ikke alle symptomene pasientene har, fanges opp. Det kommer også frem at egne kliniske vurderinger ofte vektlegges fremfor vurderinger dokumentert med ESAS. Forskning viser at helsepersonell ofte undervurderer pasientens symptomopplevelse, noe som styrker argumentet for å bruke selvrapporteringsverktøy $(2,10,11)$.

\section{三 «Det vil være vanskelig å følge pasientens symptomer over tid hvis ESAS ikke dokumenteres rutinemessig.»}

Når sykepleierens kartlegging ikke reflekterer pasientens symptomopplevelse, er det vanskelig å iverksette målrettede tiltak som lindrer pasientens symptomer. Videre vil det være vanskelig å følge pasientens symptomer over tid hvis ESAS ikke dokumenteres rutinemessig.

Det kan dermed tolkes som at variert bruk reduserer skjemaets nytteverdi og anvendbarhet. Det er derfor av betydning at sykepleierne er innforstått med hvilket ansvar de har når de bruker ESAS, og klar over at varierende bruk kan motvirke skjemaets formål.

Sykepleierne peker på flere potensielle barrierer og tiltak for rutinemessig bruk av ESAS. Disse samsvarer med resultater i tidligere forskning (2, 10, 14-16, 20-23, 25, 28, 29). Resultatene kan tyde på at det er behov for å identifisere og løse opp i barrierer som hindrer rutinemessig bruk, hvis ESAS skal bidra til systematisk kartlegging. 
Sykepleiernes erfaringer støttes av flere systematiske oversiktsartikler $(14,16)$. Artiklene vektlegger hvor viktig det er å identifisere barrierer som hemmer og faktorer som fremmer implementering og bruk av selvrapporteringsverktøy, som ESAS, i palliativ praksis.

Selv om sykepleiere kan se en tydelig verdi av ESAS, er det vanskelig å opprettholde bruken i en hektisk hverdag, ikke minst når rutinene oppleves som uklare, og manglende bruk ikke får konsekvenser for helsepersonellet. Rutinemessig bruk av ESAS blir spesielt vanskelig når det er opp til hver enkelt sykepleier å vurdere hvordan ESAS skal brukes, og hvorvidt de skal bruke ESAS konsekvent.

Når sykepleierne heller ikke kan stole på at sykepleiere på neste vakt følger opp ESAS, kan det bli vanskelig å opprettholde rutinene. Det vil også være utfordrende når sykepleierne tilsynelatende ofte har ansvaret for å engasjere andre faggrupper, og når ledelsen og/eller ressurspersoner viser liten interesse for ESAS.

På den annen side, dersom sykepleierne visste at ledelsen, ressurspersoner, andre faggrupper eller sykepleierkolleger forventer å få ESAS som en del av rapporten eller journalen, vil ESAS bli et selvsagt verktøy som er enkelt og nødvendig å bruke. Resultatene kan derfor indikere at fremtidig forskning bør vektlegge å identifisere barrierer og evaluere forebyggende tiltak hvis ESAS skal bidra til systematisk kartlegging.

\section{Studiens begrensninger}

En studie med seks informanter kan ikke generaliseres. Informantene er fra onkologiske sengeposter. Vi ville muligens fătt et noe varierende resultat dersom informantene var fra rene palliative sengeposter. En annen faktor er at flertallet av informantene hadde lang yrkeserfaring og relevant spesialisering. Det kan tenkes at sykepleiere med mindre erfaring og/eller uten spesialisering kunne gitt et annet resultat.

Likevel må vi kunne anta at funnene har en viss overførbarhet til liknende settinger og kan således ha en ekstern validitet (18). Siden informantene bruker verktøyet i hverdagen, må vi også kunne anta at deres erfaringer er troverdige og derfor har en indre validitet (19). Videre har informantene kjennskap til og erfaringer med bruk av ESAS, noe som bør kunne bidra til studiens pålitelighet (19). 
Til slutt må det nevnes at vi jobber innenfor palliasjonsfeltet. Dette kan ha vært en hindring da vi skulle tolke det sykepleierne fortalte, men kan også ha vært en positiv mulighet til å forstå sykepleiernes anliggende $(18,19)$.

\section{Konklusjon}

ESAS beskrives som et nyttig verkt $\varnothing \mathrm{y}$ for å kartlegge symptomer hos den aktuelle pasientgruppen, som igjen fremmer bedre symptomlindring og livskvalitet for pasientene. Rutinemessig bruk vektlegges for å oppnå skjemaets formål. Likevel brukes ESAS i varierende grad, noe som påvirker hvorvidt skjemaet bidrar til å systematisere symptomkartleggingen.

Studien viser til flere barrierer og tiltak for rutinemessig bruk av ESAS. Kvalitativ forskning rundt temaet er begrenset, og det er behov for ytterligere forskning på feltet. Resultatet $\mathrm{i}$ denne studien antyder fire faktorer som kan bidra til forbedret bruk av ESAS i praksis:

- Tydeliggjøring og konsensus om rutiner på tvers av avdelingen rundt bruken av ESAS.

- $\varnothing \mathrm{kt}$ s $\varnothing$ kelys på ESAS i undervisningssammenhenger, slik at det blir en større tverrfaglig, felles forståelse av skjemaets formål, relevans og bruk.

- $\varnothing \mathrm{kt}$ bevisstgjøring av den enkeltes og hver faggruppes ansvar for ESAS ut fra deres forventede ansvarsområde.

- Tydelig engasjement fra ressurspersoner og ledelsen som fremmer rutinemessig bruk av ESAS, der konsekvenser for manglende bruk blir synlig.

\section{Referanser}

1. Helsedirektoratet. Nasjonalt handlingsprogram for palliasjon i kreftomsorgen. Nasjonal faglig retningslinje. Oslo; 2015. IS-2800. Tilgjengelig fra: https://helsedirektoratet.no/retningslinjer/nasjonalthandlingsprogram-med-retningslinjer-for-palliasjon-ikreftomsorgen (nedlastet 10.05 2018).

2. Chang VT, Smith TJ, Savarese DM. Approach to symptom assessment in palliative care. Alphen aan den Rijn: Wolters Kluwer; 2018. Tilgjengelig fra: https://www.uptodate.com/contents/approach-to-symptomassessment-in-palliative-care (nedlastet 20.05 2018). 
3. Deshields TL, Potter P, Olsen S, Liu J, Dye L.

Documenting the symptom experience of cancer patients.

Journal of Supportive Oncology. 2011;9(6):216-23.

4. Kaasa S, Loge JH. Diagnostikk innen palliasjon - en

generell innføring I: Kaasa S, Loge JH, red. Palliasjon: Nordisk

lærebok. 3. utg. Oslo: Gyldendal Akademisk; 2016. s. 202-16.

5. Sæteren B. Omsorg for alvorlig syke og døende pasienter: sorg og sorgarbeid. Kreftsykepleie: pasient, utfordring, handling. 4. utg. Oslo: Cappelen Damm Akademisk; 2017. s. 224-50.

6. White C, McMullan D, Doyle J. «Now that you mention it, doctor ... »: symptom reporting and the need for systematic questioning in a specialist palliative care unit. Journal of Palliative Medicine. 2009;12(5):447.

7. Hui D, Bruera E. The Edmonton Symptom Assessment System 25 years later: past, present, and future developments. Journal of Pain and Symptom Management. 2017;53(3):63043 .

8. Verdens helseorganisasjon (WHO). WHO definition of palliative care. Genève; 2002. Tilgjengelig fra: http://www.who.int/cancer/palliative/definition/en/ (nedlastet 20.05 2018).

9. Oslo universitetssykehus HF. ESAS - Edmonton Symptom Assessment System. Oslo; 2018. Tilgjengelig fra: http://www.helsebiblioteket.no/fagprosedyrer/ferdige/esasedmonton-symptom-assessment-system--260510 (nedlastet 01.07.2018).

10. Rhondali W, Hui D, Kim SH, Kilgore K, Kang JH, Nguyen L, et al. Association between patient-reported symptoms and nurses' clinical impressions in cancer patients admitted to an acute palliative care unit. Journal of Palliative Medicine. 2012;15(3):301.

11. Laugsand EA, Sprangers MAG, Bjordal K, Skorpen F, Kaasa S, Klepstad P. Health care providers underestimate symptom intensities of cancer patients: a multicenter European study. Health and Quality of Life Outcomes. 2010;8:104. 
12. Bruera E, Kuehn N, Miller MJ, Selmser P, Macmillan K.

The Edmonton Symptom Assessment System (ESAS): a simple method for the assessment of palliative care patients. Journal of Palliative Care. 1991;7(2):6-9.

13. Watanabe SM, Nekolaichuk CL, Beaumont C. The Edmonton Symptom Assessment System, a proposed tool for distress screening in cancer patients: development and refinement. Psycho-Oncology. 2012;21(9):977-85.

14. Antunes B, Harding R, Higginson IJ. Implementing patient-reported outcome measures in palliative care clinical practice: a systematic review of facilitators and barriers. Palliative Medicine. 2014;28(2):158-75.

15. Fitch MI, Howell D, McLeod D, Green E. Screening for distress: responding is a critical function for oncology nurses. Canadian Oncology Nursing Journal. 2012;22(1):12.

16. Sommerbakk R, Haugen DF, Tjora A, Kaasa S, Hjermstad MJ. Barriers to and facilitators for implementing quality improvements in palliative care - results from a qualitative interview study in Norway. BMC Palliative Care. 2016;15(1).

17. Reitan AM. Kreftsykepleie. I: Reitan AM, Schølberg T, red. Kreftsykepleie: pasient - utfordring - handling. 4. utg. Oslo: Cappelen Damm Akademisk; 2017. s. 33-47.

18. Malterud K. Kvalitative metoder i medisinsk forskning: en innføring. 4. utg. Oslo: Universitetsforlaget; 2017.

19. Christoffersen L, Johannessen A, Tufte PA, Utne I. Forskningsmetode for sykepleierutdanningene. Oslo: Abstrakt forlag; 2015.

20. Green E, Yuen D, Chasen M, Amernic H, Shabestari O, Brundage M, et al. Oncology nurses' attitudes toward the Edmonton Symptom Assessment System: results from a large cancer care Ontario study. Oncology Nursing Forum. 2017;44(1):116-25.

21. Pereira JL, Chasen MR, Molloy S, Amernic H, Brundage MD, Green E, et al. Cancer care professionals' attitudes toward systematic standardized symptom assessment and the Edmonton Symptom Assessment System after large-scale population-based implementation in Ontario, Canada. Journal of Pain and Symptom Management. 2016;51(4):66272.e8. 
22. Bainbridge D, Seow H, Sussman J, Pond G, Martelli-Reid L, Herbert C, et al. Multidisciplinary health care professionals' perceptions of the use and utility of a symptom assessment system for oncology patients. Journal of Oncology Practice. 2011;7(1):19.

23. Myhra CB, Grov EK. Sykepleieres bruk av Edmonton Symptom Assessment Scale (ESAS): palliativ behandling. Sykepleien Forskning. 2010;5(3):210-8. DOI:

10.4220/sykepleienf.2010.0113

24. Selby D, Chakraborty A, Myers J, Saskin R, Mazzotta P, Gill A. High scores on the Edmonton Symptom Assessment Scale identify patients with self-defined high symptom burden. Journal of Palliative Medicine. 2011;14(12):1309-16.

25. Carli Buttenschoen D, Stephan J, Watanabe S, Nekolaichuk C. Health care providers' use and knowledge of the Edmonton Symptom Assessment System (ESAS): is there a need to improve information and training? Supportive Care in Cancer. 2014;22(1):201-8.

26. Martinsen K. Samtalen, skjønnet og evidensen. Oslo: Akribe; 2005.

27. Chen J, Ou L, Hollis SJ. A systematic review of the impact of routine collection of patient reported outcome measures on patients, providers and health organisations in an oncologic setting. BMC Health Services Research. 2013;13(1).

28. Dudgeon D, King S, Howell D, Green E, Gilbert J, Hughes E, et al. Cancer Care Ontario's experience with implementation of routine physical and psychological symptom distress screening. Psychooncology. 2012;21(4):357.

29. Beddard-Huber E, Jayaraman J, White L, Yeomans W. Evaluation of the utility of the Edmonton Symptom Assessment System (revised) Scale on a tertiary palliative care unit. Journal of Palliative Care. 2015;31(1):44-50. 